Res Publica Revista de Historia de las Ideas Políticas ISSN: $1131-558 \mathrm{X}$

https://dx.doi.org/10.5209/rpub.72652

\title{
Sobre la dialéctica trabajo productivo e improductivo hoy
}

Guillermo Hernández Porras ${ }^{1}$

Recibido: 25-03-2021 / Aceptado: 08-11-2021

Resumen. En este escrito voy a tratar de recuperar para el presente las nociones marxianas de trabajo productivo e improductivo, con el objetivo de, a través de una crítica a la posiciones iniciadas por Negri en relación al trabajo productivo, iluminar el presente desde la óptica de la teoría del colapso de Robert Kurz. De esta forma, lo que pretendo es una reorientación de los planteamientos respecto de estas categorías marxianas hoy para realizar una teoría crítica del capitalismo a la altura del presente en descomposición.

Palabras clave: valor; Marx; Negri; trabajo improductivo; colapso.

\section{[en] On the Dialectic of Productive and Unproductive Labour Today}

\begin{abstract}
In this paper I will try to recover for the present the Marxian notions of productive and unproductive labour, with the aim of, through a critique of the positions initiated by Negri in relation to productive labour, illuminating the present from the perspective of Robert Kurz's theory of collapse. In this way, what I intend is a reorientation of the approaches to these Marxian categories today in order to realise a critical theory of capitalism at the level of the decomposing present.

Keywords: Value; Marx; Negri; unproductive labour; collapse.
\end{abstract}

Sumario: 1. Introducción. 2. Trabajo productivo e improductivo en Marx. 3. La ampliación del trabajo productivo en Negri. 4. El trabajo productivo e improductivo a la luz de la teoría de la desustancialización del valor. 5. Breve comentario final. Bibliografía.

Cómo citar: Hernández Porras, G. (2021). Sobre la dialéctica trabajo productivo e improductivo hoy. Res Publica. Revista de Historia de las Ideas Políticas, 24(3), 419-430.

\section{Introducción}

“(...); el búho de Minerva sólo alza el vuelo en el ocaso", escribía Hegel en el prólogo de sus Principios de Filosofía del Derecho ${ }^{2}$. En palabras de Jappe, esta frase tiene su aplicación al tema que me ocupa aquí: "hoy se puede determinar mejor la cuestión del trabajo productivo"3. Esto es lo que voy a tratar de hacer en este escrito: intentar mostrar la dialéctica entre trabajo productivo e improductivo a partir de estas categorías del análisis marxiano ${ }^{4}$, con el objeto de comprender mejor el presente y poder clarificar la orientación a este respecto de la teoría crítica del capitalismo. Para ello es necesario tener un cierto cuidado cuando se menciona a Marx, ya que es un autor que ha sido o bien frecuentemente malinterpretado, o bien se presta a las más diversas interpretaciones. Por ello, partiré de la premisa de la crítica de la escisión del valor de que existe un "doble Marx": uno "exo- térico" y otro "esotérico" 5 . Para los autores de esta corriente existe un Marx de la lucha de clases, teórico de la explotación, ontólogo del trabajo, etc. En resumidas cuentas, es un Marx ciertamente transhistórico para el que ciertas categorías se corresponden con ese metabolismo con la naturaleza que, supuestamente, estaría presente en las distintas épocas históricas o modos de producción. Este Marx, aunque está ahí, carece de interés para los planteamientos kurzeanos. Para mí también.

En cambio, el Marx que me va a interesar aquí es el que indica que su pretensión es la de "revelar la ley del movimiento de la sociedad moderna" $\mathrm{y}$ de ninguna otra. De esta forma vemos que la base marxiana aquí utilizada es aquella para la cual todo el análisis categorial de la forma valor, todas las dualidades como valor de uso y valor de cambio, trabajo concreto y trabajo abstracto, trabajo productivo e improductivo, son dualidades de la propia forma

\footnotetext{
Universidad Autónoma de Madrid

Email: guillermo.hernandezp@uam.es

G. W. F. Hegel, Principios de la Filosofia del Derecho o Derecho Natural y Ciencia Política, Barcelona, Edhasa, 1999, p. 63.

A. Jappe, Las aventuras de la mercancía, Logroño, Pepitas de Calabaza, 2016, p. 127.

Si bien es cierto que esta expresión no está directamente en Marx, trataré de desarrollar que es sumamente pertinente para el análisis de esta cuestión.

A. Jappe, op. cit., p. 18.

6 K. Marx, El capital, Madrid, Akal, 2014, Prólogo a la primera edición alemana, p.18.
} 
mercancía y, por tanto, histórico específicas. Por lo tanto, debo resaltar aquí que el que va a servir de fundamento es un Marx dialéctico, para el que estas dualidades son inseparables, es decir, no puede haber trabajo productivo sin trabajo improductivo, como no puede haber valor de uso sin valor de cambio. No es posible escindir, como hizo gran parte del pensamiento del movimiento obrero, una dimensión supuestamente ontológica de una dimensión histórico específica. La propia realidad de la forma mercancía es dialéctica en sí misma y, por tanto, tiene una especificidad histórica restringida al entramado de socialización capitalista. Sin embargo, no podemos decir que esta sea la única interpretación posible de Marx ya que él mismo ha incurrido en esa aporía $^{7}$ que se presta a la absurda ontologización tan característica del marxismo tradicional ${ }^{8}$. Esta aporía se extiende, por desgracia, al tema que aquí me ocupa.

Sin embargo, no trato de realizar un trabajo de marxología o de filología marxiana, sin que esto signifique que los planteamientos aquí esbozados no tienen una base en los propios textos de Marx, sino que trataré de ocuparme, como ya he aludido en el título, de la dialéctica de trabajo productivo e improductivo hoy. Lo que me interesa es poder interpretar esta dialéctica a la luz de la teoría del colapso por desustancialización del valor elaborada por Robert Kurz y, desde ahí, realizar una crítica de la posturas que han tratado de expandir la noción de trabajo productivo, tal como hicieron Negri y algunos de sus contemporáneos y continuadores (Virno, Federici, Vercellone, etc.), lo que ha llevado al extremo de que se llegue, incluso, a escribir sobre una supuesta explotación "más allá del salario"9. Trataré finalmente de alertar de los peligros de eludir o no prestar suficiente atención a la cuestión del trabajo productivo e improductivo hoy.

Para todo ello será necesario, en primer lugar, un repaso más o menos detallado de las nociones de trabajo productivo e improductivo en el propio Marx, así como un cierto análisis de la estrategia de $\mathrm{Ne}$ gri y algunas de las continuaciones que ha tenido, mostrando los errores teóricos ya respecto del propio Marx. Por último, será también necesario un breve rodeo por la teoría del colapso de Kurz, para poder desembocar en la interpretación de la dialéctica trabajo productivo e improductivo como uno de los síntomas del colapso. Llegados a ese punto, podremos observar las consecuencias de desvirtuar el análisis teórico de Marx respecto del trabajo productivo e improductivo.

\section{Trabajo productivo e improductivo en Marx}

Si bien es cierto que Marx no inventa estas categorías, ya que las toma prestadas de la economía política clásica, no entraré en su disputa con los clásicos de dicha disciplina. Así que, lo mejor es dar la palabra directamente a la propia interpretación de Marx en relación a esta cuestión:

Mas, por otra parte, se restringe el concepto de trabajo productivo. La producción capitalista no es sólo producción de mercancías, sino que esencialmente es producción de plusvalía. El obrero no produce para sí sino para el capital. Por tanto, ya no basta con que produzca en términos generales. Tiene que producir plusvalía. Sólo es productivo el obrero que produce plusvalía para el capitalista o que sirve para la autovalorización del capital. Si se nos permite un ejemplo fuera de la esfera de la producción material, un maestro de escuela será productivo no sólo cuando elabora las mentes de los niños, sino cuando moldea su propio trabajo para enriquecer al empresario. El que este último haya invertido su capital en una fábrica de enseñanza en vez de en una fábrica de salchichas, no cambia en nada la relación ${ }^{10}$.

De este pasaje debe quedarnos claro que para Marx el trabajo productivo es aquel que produce para el capital, no para el obrero mismo ni para el capitalista en forma de servicios personales. Es decir, que no basta con producir valor de uso ${ }^{11}$, sea para quien sea, sino que tiene que producirse con vistas a la valorización del valor. De esta forma, queda claro que trabajo productivo es aquel que produce plusvalor. Por tanto, "un trabajo de idéntico contenido puede ser productivo e improductivo"12; ya que, como veíamos en el ejemplo, el mismo profesor, en la misma aula y con los mismos alumnos, puede ser improductivo si no es un trabajador asalariado para el capital. El carácter productivo del trabajo está restringido a la producción de plusvalor, de tal modo que estas categorías de trabajo productivo e improductivo: "son características del punto de vista capitalista"13; son histórico específicas. Sin embargo, hemos podido leer en el pasaje mencionado a modo de ejemplo, que Marx habla ahí de una reducción de la noción de trabajo productivo. Vemos aquí esa aporía de la que hablábamos, puesto que para un cierto Marx las nociones de trabajo productivo e improductivo son histórico específicas y, a su vez, son una restricción del trabajo productivo en sentido general, en aquel que mencionábamos en la introducción respecto del intercambio metabólico. No me interesa éste último.

R. Kurz, The Substance of Capital, Londres, Chronos publications, 2016, p. 27. Existe ya una traducción de este libro al castellano (La sustancia del capital, Madrid, Enclave de Libros, 2021).

M. Postone, Marx reloaded, Madrid, Traficantes de Sueños, 2007, p. 26

F. Chicci, E. Leonardi y S. Lucarelli, Más allá del salario: lógicas de explotación, Madrid, Enclave de Libros, 2018.

K. Marx, El capital, op. cit., Libro I, segundo tomo, p. 255.

Ibidem, primer tomo, p. 63.

Ibidem, Capitulo VI (inédito). Resultados del proceso inmediato de producción, México, Siglo XXI, 1971, p. 84.

Ibidem, p. 82 
Me interesa retener aquí que para Marx no todo el trabajo que se realiza en el entramado de socialización capitalista es trabajo productivo. De entrada, sólo el trabajo que produce para el capital, independientemente de su contenido, es trabajo productivo.

Sin embargo, Marx también nos indica: "todo trabajador productivo es un asalariado, pero no todo asalariado es un trabajador productivo" ${ }^{4}$. Aquí llegamos al punto crucial del análisis, ya que resulta que aunque todo trabajo productivo es asalariado, de lo contrario no produciría bajo el mandato del capital, no todo trabajo asalariado es productivo. Para comprender esto mejor, es necesario tratar someramente la compleja cuestión de dónde surge el valor $\mathrm{y}$, por ende, el plusvalor. Pues bien, frente a todos aquellos teóricos que habían creído (y siguen creyendo ${ }^{15}$ ) que el valor surgía del propio intercambio, Marx indica: "la circulación o el intercambio de mercancías no crea ningún valor"'16, es más, en relación a la esfera de la circulación no indica que: "el valor de las mercancías se representa en sus precios antes de que entren en circulación, por lo tanto, es premisa y no resultado de la misma" "17. En mi opinión, a pesar de la dificultad de la cuestión, para Marx existen diferencias entre la objetividad del propio valor y su forma de aparición. Marx establece mediaciones entre esa esencia y esa apariencia $^{18}$, es decir, valor y valor de cambio no son idénticos, como tampoco lo son valor de cambio y precio de producción ${ }^{19}$. Realizar una identificación entre estas dualidades es tanto como caer en "la noche en la que, como suele decirse, todos los gatos son pardos, es la ingenuidad del vacío en el conocimiento" ${ }^{20}$. Marx, muy buen conocedor de Hegel, no caería en semejante insuficiencia teórica. En la producción, las mercancías, aunque suene tautológico, son producidas; mientras que en la circulación, son realizadas, en esta esfera se validan las distintas cantidades de trabajo contenidas en ellas. Igual de importante es la producción de valor que su realización, ninguna existiría sin la contraria ${ }^{21}$.
Después de este pequeño pero fundamental rodeo, podemos llegar a la siguiente conclusión: todo trabajo que tenga lugar en la esfera de la circulación (o los dos actos de la circulación, como lo define Marx a la inicio del Libro II de El capital) será improductivo. Hasta el punto de que Marx llega a enunciar una "ley general" en la que "todos los gastos de circulación que emanan solamente del cambio de forma de la mercancía no añaden a ésta ningún valor" ${ }^{22}$. Todos aquellos trabajos que tengan lugar en lo que Marx denomina esfera de la circulación serán improductivos, aunque sean asalariados y se realicen para un capitalista que está empleando su capital con fines de valorización. Marx, incluso, llega a decir: "los funcionarios pueden convertirse en asalariados del capital, pero no por ello se transforman en trabajadores productivos" ${ }^{\prime 23}$. Es decir, aún realizando la misma tarea para el capital seguirían siendo improductivos. Es el propio contenido concreto de la tarea que está destinado al cambio de forma de la mercancía, al proceso de compraventa, o al mantenimiento del valor de la propia mercancía lo que también determina el carácter improductivo del trabajo. Vemos que más ex cierta inconsistente con los que nos decía anteriormente respecto del contenido del trabajo en relación a si es productivo o no lo es.

Además, existen toda una serie de tareas llamadas por Marx faux frais de production ${ }^{24}$, que tampoco producen valor. De forma que tenemos (aunque Marx no elabore esta separación estricta y sólo nos sirva aquí con carácter aclaratorio) una doble clasificación de tareas improductivas: las pertenecientes a la esfera de la circulación y los faux frais de production. En relación con las primeras, encontramos todas las funciones comerciales ${ }^{25}$, de venta, a lo que podríamos añadir las de marketing ${ }^{26}$, publicitarias, etc.; además de todas las cuestiones jurídicas y notariales entre "adquirientes y vendedores" 27 . Mientras que, entre los segundos encontramos las tareas de supervisión y dirección de la producción ${ }^{28}$, los gastos de almace-

14 Ibidem, p. 80 (cursivas mías). Adviértase aquí que en el párrafo anterior hemos visto decir a Marx que el contenido del trabajo era indiferente de la producción de valor y, en cambio, ahora nos indica que dentro del trabajo que produce para el capital, hay trabajos que no producen valor.

Cf. la interesante y severa crítica que Kurz realiza sobre este tema a Henrich en The Susbtance of Capital (op. cit., p. 74 ss).

16 K. Marx, El capital, op. cit, Libro I, primer tomo, p. 220. Marx no es siempre del todo coherente en esta cuestión. Sin embargo, por motivos de espacio no puedo detenerme más en ella.

Ibidem., p. 213.

8 R. Kurz, The Substance of capital, op. cit., pp. 74-76.

19 A pesar de que no puedo abarcar aquí toda la complejidad del problema valor-precio de producción, me parece que Marx era muy consciente de esta dialéctica no idéntica entre ambos. Incluso, si se quiere, de una dialéctica negativa: "La forma acabada de las relaciones económicas, tal como se presenta en la superficie, en su existencia real y, por tanto, también en las ideas con que los portadores y agentes de estas relaciones procuran ver claro en ellas, difiere mucho y es, en realidad, lo inverso, lo contrario a su forma nuclear interna, esencial, pero oculta, y al concepto que le corresponde" (K. Marx, El capital, op. cit., Libro III, primer tomo, p. 261).

20 G. W. F. Hegel, Fenomenología del espíritu, Madrid, Fondo de Cultura Económica, 1966, p. 15.

21 K. Marx, El capital, op. cit., Libro II, primer tomo, p. 158.

22 Ibidem, p. 186 (cursivas en el original). Si bien Marx en este libro se está ocupando del proceso de circulación del capital, en esta referencia alude al cambio de forma de la mercancía, tal y como ya ha indicado que sucede en la esfera de la circulación. Aquí Marx se está refiriendo a los gastos en la esfera de la circulación.

K. Marx, El capital. Libro I Capítulo VI (inédito). Resultados del proceso inmediato de producción, op. cit., p. 83.

Ibidem, segundo tomo, p. 30.

Ibidem, Libro II, primer tomo, p. 163.

26 K. Kurz, "The Crisis of Exchange Value: Science as Productive Force, Productive Labor, and Capitalist Reproduction" en N. Larsen, M. Nilges, J. Robinson, y N. Brown, (eds.), Marxism and the Critique of Value, Chicago, MCM' Publishing, 2014, p. 23.

27 K. Marx, El capital. Libro I Capítulo VI (inédito). Resultados del proceso inmediato de producción, op. cit., p. 83.

28 Ibidem, segundo tomo, p. 30. 
namiento $^{29}$, toda la gestión administrativa ${ }^{30}$, mantenimiento, etc.

En definitiva, todas aquellas tareas que deban tener lugar para que la producción y el cambio de forma de la mercancía en la esfera de la circulación puedan llevarse a cabo, pero que no pertenezcan al propio proceso de producción ${ }^{31}$ de la mercancía, serán improductivas. Continuando con el ejemplo de la clase, dado por el propio Marx, la mercancía es la propia clase; por lo tanto, el único trabajador productivo allí será el profesor. El personal que gestiona las admisiones y realiza las distintas gestiones de matriculación y gestión administrativa de cualquier índole, el personal de mantenimiento del edificio y de limpieza del mismo, etc., son trabajadores improductivos. Resulta evidente que sin admisión de alumnos, no hay clase. Como también que si no se limpian las aulas, tampoco habría clase. No se trata de indicar que el trabajo productivo es el verdadero trabajo en detrimento de todos los otros o que el trabajo improductivo es innecesario. Esto sólo sería posible como premisa para una reivindicación del trabajo en el sentido ontológico del mismo, cuestión que ya he mencionado que me parecería errada. Trabajo productivo e improductivo se co-necesitan, lo que no implica que debamos confundirlos. Y esta cuestión es clave, ya que como indica Marx: "la diferencia entre trabajo productivo y trabajo improductivo [es] importante con respecto a la acumulación, ya que sólo el intercambio por trabajo productivo constituye una de las condiciones de la reconversión de la plusvalía en capital"32. Es importante retener de esta cuestión que el trabajo improductivo es para el capital un mal necesario que se deriva del propio proceso de producción de valor. Si pudiera ser reducido o eliminado, tanto mejor para el capital. Lo que me conduce a plantear la última y más polémica cuestión relacionada con el tema del trabajo productivo e improductivo: el transporte. En mi opinión, Marx no es del todo claro cuando aborda la cuestión del transporte. Después de explicarnos en el Libro II de El capital los gastos netos de circulación y los de conservación como gastos, pasa a explicarnos los gastos de transporte ${ }^{33}$, llegando a argumentar de la siguiente manera:

El transporte de los productos de un centro de producción a otro va seguido por el de los productos acabados de la esfera de la producción a la del consumo. El producto no está listo para el consumo mientras no haya terminado este movimiento ${ }^{34}$.
Para Marx, el transporte es un "proceso adicional de producción"; de forma que los medios de transporte transfieren, en forma de capital constante, su valor al producto y los trabajadores de este sector lo hacen en cuanto capital variable, como sucede en cualquier proceso de producción. En última instancia, se produce en el transporte una "adición de valor" 35 . Ahora bien, si Marx tenía tan claro que el transporte producía valor, ¿por qué necesita tratarlos como gastos de transporte y los sitúa dentro de los gastos de circulación a los que ha declarado incapaces de crear ningún valor? Parece ser que para Marx la dificultad estriba en que el transporte es "un proceso de producción dentro del proceso de circulación y para el

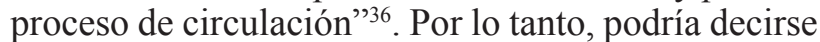
que aquí para Marx aunque puedan parecer gastos de transporte, son parte del proceso productivo.

En mi opinión, Marx podría estarse equivocando en este Libro II de El capital al incluir el transporte dentro de los procesos productivos y debería insistir en considerarlo un gasto en cuanto deducción del plusvalor, ya que el transporte no aporta nada a la producción de la propia mercancía, tal y como argumenta él mismo en los Grundrisse ${ }^{37}$. Marx es ciertamente incoherente en este punto, ya que en la sección de El capital dedicada a los gatos de transporte argumenta que, mediante el transporte el producto se transforma en mercancía ${ }^{38}$. La aporía marxiana que mencionamos anteriormente se manifiesta aquí respecto al ámbito del transporte. Si consideramos, como vimos que hace también Marx, que el valor no proviene de la esfera de la circulación, los gastos de transporte podrán seguir estando incluidos entre los gastos de circulación y su ley general declara todos los trabajos que se producen en ella como trabajos improductivos.

Se puede, por un lado, transportar el producto o ciertas partes del producto, para que el proceso de producción pueda seguir su curso o realizarse por completo; o se puede trasladar la mercancía ya totalmente producida al mercado donde es posible que sea comprada. Ninguno de ambos procesos tienen efectos sobre el proceso productivo en sí mismo, que debería ser el criterio para la producción o no-producción de valor y, por tanto, para delimitar el trabajo productivo y el improductivo. Ahora bien, no todo transporte es improductivo. En el momento en el que el desplazamiento se convierte en la propia mercancía, en el momento en que las personas "viajan con el medio de transporte, y su viaje, su movimiento en el espacio, es precisamente el proceso de producción

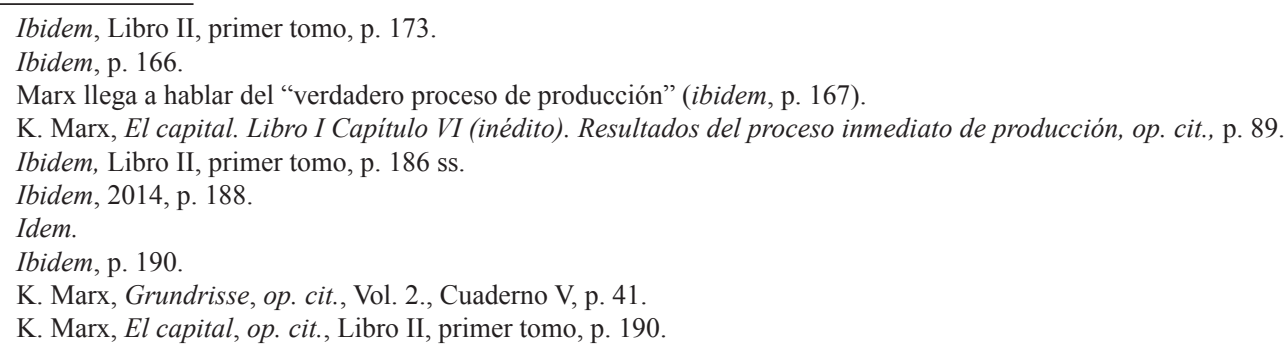


efectuado por él""39; en ese momento el proceso de producción de la mercancía es el propio transporte, ya que la mercancía es el transporte en sí mismo. En esta última cita, Marx no menciona sólo a las personas sino también "las mercancías" y es aquí donde difiero respecto de Marx. Mientras que el transporte de personas es una mercancía en sí misma, en el caso del transporte de mercancías, el transporte no es la mercancía en sí. Por lo tanto era acertado considerar los gastos de transporte como gastos y, por ende, deberían figurar dentro de la esfera de la circulación y no como parte del proceso productivo.

No obstante, lo que puede inducir a error aquí es que hay ciertas empresas o ramas empresariales que se escinden en sí mismas y pudiera parecer que se vuelven productivas al escindirse, como ya advirtió el propio Marx ${ }^{40}$. Por otro lado, todos estos trabajos pueden producir "enriquecimiento" lista particular, sin que por ello sean actividades productivas. El hecho de que una empresa particular, ya sea de transporte de mercancías, una gestoría, etc., presenten beneficios no significará que produzca valor.

Ahora bien, chocamos aquí con una cierta dificultad en el análisis: ¿qué sucede si un mismo trabajador realiza trabajo productivo e improductivo? ¿Qué sucede si un mismo trabajador realiza tareas comerciales, tareas administrativas y, además, participa o realiza el proceso productivo mismo? Esto no plantea ningún problema metodológico, ya que un mismo trabajador puede ser productivo e improductivo. Como mucho, esto puede suponer un problema para aquellos que quieran hacer estadísticas con esta cuestión, pero aquí estamos advertidos por Kurz de que:

En las ciencias sociales la matemática entra siempre en escena una vez que se ha perdido el concepto crítico y ha de posibilitarse el manejo de la descripción de una estructura social que carece de concepto ${ }^{42}$.

De esta forma no se tratará de evaluar qué trabajador es productivo y cuál no, sino de comprender que existen toda una gran serie de actividades improductivas que son cruciales para el propio proceso de producción. Ha sido Marx quien ha puesto de manifiesto esta cuestión y que, como veremos al final de este escrito, es fundamental, en mi opinión, para comprender nuestro presente.

\section{La ampliación del trabajo productivo en Negri}

La tesis fundamental a este respecto de Negri, expuesta en Marx más allá de Marx, es que, a pesar de que Marx ha ido mucho más allá en algunas cuestiones en los Grundrisse, ha mantenido "una definición tremendamente reductora" 43 del trabajo productivo. Pero, para poder entrar en esa cuestión, debemos dar un pequeño rodeo por otros aspectos de la ley del valor, que no son las categorías de trabajo productivo e improductivo pero a los que Negri presta especial atención; como por ejemplo, la relación entre trabajo concreto y abstracto o entre plusvalor $\mathrm{y}$ beneficio.

Sin embargo, antes de entrar en el análisis de esas cuestiones, debemos advertir que el propio Negri indica que no tiene necesidad "de hundir las manos en el hegelianismo para descubrir la doble cara de la mercancía, del valor: el dinero tiene una sola cara, la del patrón"44. No es, a este respecto, casualidad ni mucho menos que en el propio prólogo de Marx más allá de Marx se rinda pleitesía a Deleuze y Guatta$\mathrm{ri}^{45}$. Con esto nos queda claro que, a pesar de que Negri defina su método como "dialéctico"46, su objetivo será mostrar que, en especial la relación capital-trabajo pero no sólo, esas dualidades dialécticas, dejan de ser dialécticas, para volverse antagónicas ${ }^{47}$. Retengamos toda esta cuestión de fondo, que podría entenderse casi como una des-dialectización, basada en que llegado un punto del desarrollo del capital, no es posible la medición del valor por el tiempo de trabajo y, por tanto, "la ley del valor se extingue"48. Esto tiene una serie de consecuencias para aspectos tales como: la relación trabajo concreto-trabajo abstracto, la relación valor de uso-valor de cambio, la relación plusvalor-beneficio, la relación producción-circulación $\mathrm{y}$, por último, la relación trabajo productivo y trabajo improductivo. Trataré de esbozarlas todas ellas para poner de manifiesto algunas otras posturas similares de autores afines a los planteamientos de Negri y poder realizar una crítica de las mismas en base a lo visto en el apartado anterior basado en el propio Marx.

Respecto a la relación entre trabajo concreto y abstracto, Negri nos indica que "el concepto de trabajo se mueve en la realidad histórica de la economía hacia formas cada vez más elevadas de abstracción"49. En otras palabras del mismo Negri:

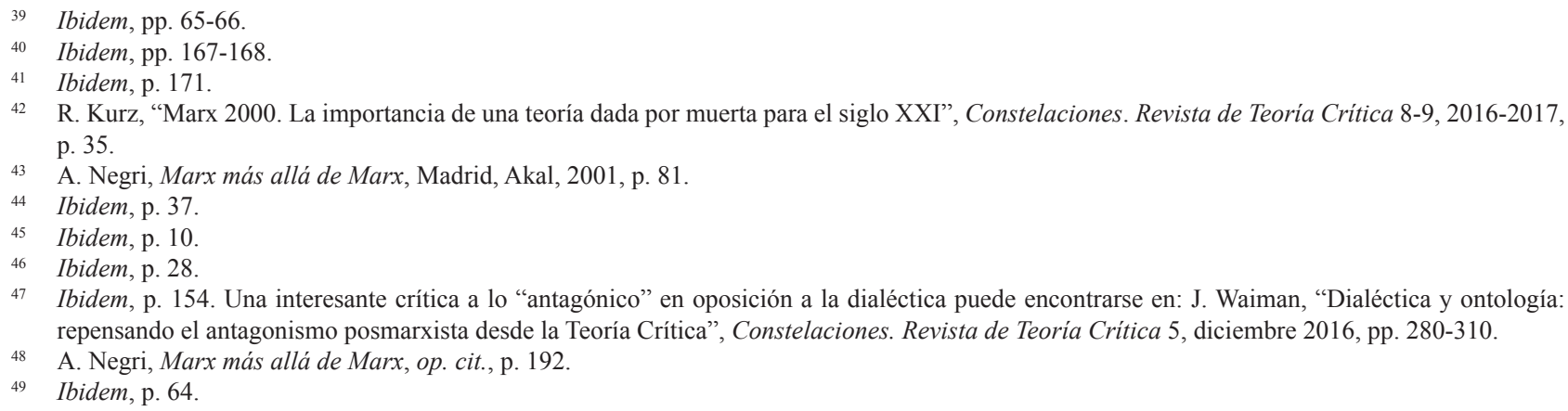


(...) cuando el capital subsume a la sociedad organizándola a su imagen y semejanza, el trabajo productivo deviene trabajo intelectual, cooperativo, inmaterial. Añade que únicamente en estas condiciones la crisis del capitalismo se hace definitiva, $y$, por consiguiente, se plantea con urgencia la cuestión del comunismo como destrucción del capital por parte de una comunidad de individuos libres y ricos. Se desprende de ello que la liberación del trabajo intelectual, como mise en forme de los procesos de producción subjetiva (fuente y matriz de valor y de riqueza), deviene en los Grundrisse la clave interpretativa del proyecto comunista ${ }^{50}$.

Aquí vemos ya mucho más claramente expuesta la cuestión. Resulta que el "trabajo productivo" ha devenido abstracto, que resulta ser lo mismo que "inmaterial". En primer lugar, habría que indicarle a Negri, como ha hecho Jappe, que:

El trabajo abstracto no es ni el trabajo en cadena ni el trabajo del informático. Por consiguiente, es erróneo decir que el trabajo abstracto "reemplaza" cada vez más al trabajo concreto o que el trabajo se hace "cada vez más abstracto" ${ }^{\circ 1}$.

Es decir, que la noción de trabajo abstracto en Marx no se refiere a la inmaterialidad del trabajo. Igual de abstracto es el trabajo manual como el intelectual. Por lo tanto, el desarrollo del capitalismo no puede conducir a un proceso de crecimiento de la abstracción en el trabajo. Como ha desarrollado Postone $^{52}$, dado que el tiempo de trabajo se mide en horas, una hora no puede volverse más abstracta. Pero a este respecto existe también otra incongruencia en el planteamiento de Negri que, por cierto, ha sido puesta de manifiesto por otro postobrerista: Sergio Bologna. La objeción que éste apunta es la siguiente:

Es un non sense (sinsentido) hablar del trabajo como de una actividad inmaterial: es probable que no existe actividad humana donde la fisicidad, el tesón, el esfuerzo, el sentido de la disciplina, la adaptación al ambiente y la flexibilidad estén sometidos a un apremio mayor que durante el ejercicio de una función laboral. No existe actividad de la que dependa en mayor medida la reproducción física del individuo, ni existe otra actividad humana por la que el capital esté dispuesto a dar una contrapartida económica del trabajo. Por lo tanto, el trabajo, de por sí, encierra la quintaesencia de la materialidad, definirlo como "inmaterial" es absurdo y da lugar a equívocos. (...) Las mercancias pueden ser inmateriales, los trabajos $n o^{53}$.

Vemos como la consistencia de las categorías de "trabajo abstracto" y "trabajo inmaterial" en Negri se van diluyendo. Hasta el punto de perder su pretendida base marxiana, ya que el propio Marx definió la fuerza de trabajo como "el compendio de aptitudes físicas e intelectuales" 54 . Primer error de Negri.

Vayamos con el segundo: la relación entre valor de uso y valor de cambio. Seguimos aquí con la dinámica de Negri de escindir dualidades dialécticas. Para ello, Negri nos espeta que: “¡Hace falta ser realmente ignorante o proceder absolutamente con mala fe para reducir el «valor de uso» (en el sentido marxiano) a un residuo o a un apéndice del desarro1lo capitalista!" 55 . Para Negri, existe, curiosamente, una dialéctica mediante la cual el capital va generando una subjetividad otra a sí mismo: el trabajo. La potencia creativa de ese trabajo es la que estaría aquí aflorando en el valor de uso. Tanto es así, que para el propio Negri "el trabajo crea sus necesidades e impone al capital que las satisfaga" ${ }^{\circ 6}$. ¡Esto sí que es de ignorantes! Resulta que para Negri no son nuestros cuerpos los que deben deformarse para entrar en los tallajes abstractos de las industrias textiles... isino que esa sería una necesidad que le imponemos al capital! Sería totalmente absurdo continuar la crítica de este incoherente aspecto del pensamiento de Negri.

El tercer error de Negri sería la operación que lleva a cabo entre plusvalor y beneficio y que, a diferencia del tipo de error que veníamos observando, este va a ser una no-diferenciación entre ambos. Lo que Negri concluye desde los Grundrisse es que "el plusvalor es beneficio" 57 . De una forma algo más desarrollada encontramos que:

Cuando el capital se ha convertido históricamente en capital social, el beneficio ya no puede ser mediación: es mediación resuelta, es plusvalor social, es la sigla capitalista de una relación antagonista que implica realmente la totalidad de la sociedad ${ }^{58}$.

Para Negri no existen ya las mediaciones entre esencia y apariencia. Cuando el capital alcanza cierto punto, el beneficio es ya "mediación resuelta", el plusvalor, automáticamente se convierte en beneficio. Quizás Negri debía haber prestado atención al siguiente pasaje de Marx:

Ibidem, p. 8.

A. Jappe, op. cit., p. 50.

M. Postone, Tiempo, trabajo y dominación social, Madrid, Marcial Pons, 2006, pp. 380 y ss.

S. Bologna, Crisis de la clase media y postfordismo, Madrid, Akal, 2006, p. 128. Recientemente ha realizado también Clara Navarro una crítica del "capitalismo cognitivo" ciertamente interesante ("¿Qué fue de...? Breves apuntes sobre el capitalismo cognitivo y el modo de producción capitalista en el siglo XXI", Res Publica. Revista de Historia de la Ideas Políticas 23(1), pp. 97-108).

K. Marx, El capital, op. cit., 2014, Libro I, primer tomo, p. 225.

A. Negri, op. cit., p. 86.

Ibidem, p. 151.

Ibidem, pp. 106-107.

Ibidem, p. 105. 
Como en la cuota de ganancia la plusvalía se calcula sobre el capital global y se refiere a éste como medida suya, la plusvalía misma parece así como derivada del capital global y, concretamente, como si emanase por igual de todas sus partes, de modo que se borra la diferencia orgánica entre capital constante y variable en el concepto de ganancia; por eso, en realidad, bajo ésta su forma transfigurada de ganancia, la propia plusvalía niega su origen, pierde su carácter, se hace irreconocible ${ }^{59}$.

La diferencia entre plusvalor y beneficio es clave para Marx. Precisamente esto es lo que no hicieron los economistas clásicos y, por ello mismo no pudieron realizar una crítica de la economía política. En los mismos Grundrisse, Marx sentencia que "en el concepto de valor se delata su secreto" ${ }^{\circ 0}$ : el del capital. Por lo que para Marx el plusvalor nunca podrá ser automáticamente beneficio y, por eso, está interesado en la relación de no-identidad entre ambos. He aquí el tercer y uno de los más graves errores de Negri: identificar plusvalor y beneficio.

Esto me lleva al cuarto error: la relación producción-circulación. Muy en línea con la estrategia llevada en el error anterior, Negri dictamina que "la apropiación capitalista de la circulación, apropiación cada vez más totalitaria, determina la circulación como fundamento de la producción y de la reproducción, hasta un límite de identificación histórica, efectiva (aunque no lógica) de producción y circulación" ${ }^{61}$. Digamos que en el proceso de colonización total del capital se produce, para Negri, otra inmediatez, otra identificación casi total: la esfera de la circulación y la esfera de la producción se hacen en realidad indistinguibles. Ya vimos que para Marx la esfera de la circulación quedaba estrictamente excluida de la producción de valor, pero no es así para Negri. Esta identificación lleva a Negri incluso a hablar de "circulación productiva" 62 y a indicar que:

La circulación productiva recoge en la cadena de montaje del capitalismo social todo el trabajo social en otro caso definido como directa o indirectamente, inmediata o mediatamente productivo. (...) La extensión del concepto y de la realidad del trabajo productivo, en la circulación, en la reproducción, muestra, por otro lado, no únicamente la historicidad, sino la variedad multilateral del proceso constitutivo de la individualidad histórica del sujeto comunista. Bien, este progreso definitorio era posible para Marx en el nivel actual de su desarrollo teórico. Pero no se produce. La definición marxiana del trabajo productivo es, por el contrario, una definición reductora, ligada a la axiología socialista del trabajo manual. Condicionada por ésta, aunque todas las condiciones teóricas habían cambiado ${ }^{63}$.

Para Marx, hablar de "circulación productiva" era algo impensable. Por lo que comentaré directamente el último error de Negri y el que más me interesa: la relación entre trabajo productivo e improductivo. Como vimos al principio, a Negri le parecía que la definición de Marx era muy reduccionista; es decir, que había que ampliarla. En este sentido, una vez escindido el valor del uso del valor de cambio, una vez se ha identificado el plusvalor con el beneficio y la circulación con la producción: todo trabajo tiene que aparecer como trabajo productivo. La consecuencia teórica de esta interpretación de la ley del valor es que todo trabajo pasa a ser inmediatamente productivo en cuanto "trabajo inmaterial". Su objetivo es eliminar toda una serie de mediaciones con el fin de crear una clase trabajadora heterogénea pero unida en la lucha. Lo que ha conducido a que, como bien ha resumido Jappe, Negri (junto con Hardt) ha llevado a cabo un totum revolutum en el que se vuelve imposible distinguir entre trabajo productivo y trabajo improductivo $^{64}$. En ningún caso esto podía ser la intención de Marx y, además, esto puede observarse en las desviaciones teóricas que se han podido producir al hilo de estas posiciones de Negri. Por ejemplo, tenemos la invención del "trabajo doméstico" por parte de Federici65; la afirmación de Virno de que "Marx acepta la ecuación trabajo-sin-obra igual a servicios personales"66; así como también Bologna, en su libro Crisis de la clase media y postfordismo, alude a que el trabajo autónomo no ha sido ciertamente considerado por Marx o que escaparía a sus planteamientos de clase ${ }^{67}$ y ha buscado mostrar la logística ${ }^{68}$ como el nuevo funcionamiento productivo del capital.

Igual que Negri se equivocaba, lo hace Federici ya que, en palabras de Roswitha Scholz "las actividades reproductivas femeninas tienen en el capitalismo un carácter diferente al del trabajo abstracto; por tanto no se las puede subsumir sin más bajo el concepto de trabajo"69. A Virno, le responde el propio Marx que alude a una "manía de definir el trabajo productivo y el improductivo con arreglo a su contenido material"'70, lo que imposibilita decir que Marx haya res-

\footnotetext{
K. Marx, El capital, op. cit., Libro III, primer tomo, p. 217.

K. Marx, Grundrisse, op. cit., Vol. 2, Cuaderno VII, p. 315.

A. Negri, op. cit., p. 131.

Ibidem, p. 51.

Ibidem, p. 203.

A. Jappe, op. cit., p. 223.

S. Federici, El patriarcado del salario, Madrid, Traficantes de Sueños, 2018, p. 13.

P. Virno, Gramática de la multitud, Madrid, Traficantes de Sueños, 2016, p. 53.

S. Bologna, op. cit., p. 28.

Ibidem, p. 119.

69 R. Scholz, "El patriarcado productor de mercancías. Tesis sobre capitalismo y relaciones de género", Constelaciones. Revista de Teoría Crítica 5, diciembre 2016, p. 48.

70 K. Marx, El capital. Libro I Capítulo VI (inédito). Resultados del proceso inmediato de producción, op. cit., pp. 86-87.
} 
tringido el trabajo productivo a la producción material: esto es literalmente falso. También Bologna es respondido por el propio Marx, ya que sí que trata, aunque no dedique especial atención, al self-employing labourer ${ }^{71}$, como lo llama él mismo y del que determina su improductividad. Quizás Marx no pudo tener en cuenta al falso autónomo, pero no podemos culparle por ello. Y no porque en su época no se diera y este sea un fenómeno característico del postfordismo, sino porque el falso autónomo no es ni más ni menos que la nueva máscara de carácter del trabajador en el capitalismo en colapso. Pero el error más claro de Bologna es orientar su investigación hacia la logística y darse cuenta de que ésta ha cambiado de una logística productiva a una distributiva o circulatoria, sin haberse percatado de la no-producción de valor de estos trabajo. Los reyes de la logística son, tal y como indica el propio Bologna: "Wal-Mart en Estados Unidos, Metro en Alemania, Auchan y Carrefour en Francia"72. Todos ellos se dedican a tareas vinculadas a la compraventa de mercancías, a su almacenamiento, transporte, empaquetado, etc. Hemos podido ver que, a excepción del transporte, el propio Marx las habría clasificado como improductivas.

Por otro lado, nos encontramos la reciente compilación llevada a cabo por Eva Illouz ${ }^{73}$ con el objeto de análisis de lo que han llamado "emmodity" o "commodity emocional"74. Asumiendo las posturas que hemos mostrado de Negri, llegan a afirmar que como el trabajo material está siendo prácticamente eliminado o es insignificante, la mayor parte de "valor agregado" proviene del "branding/publicidad"75. De forma que el propio acto de consumo, ya que la mayoría de mercancías o commodities son experienciales y no ya objetuales (según la propia Illouz), el acto de consumo queda dotado de una cierta "performatividad"76. Un buen resumen de esta posición sería la siguiente frase de Kaplan en el libro previamente aludido de Illouz: "el trabajo productivo ya no está confinado al lugar de trabajo tradicional, sino que se ha expandido hasta incluir la vida misma" "77. Simplemente con lo visto ya en el apartado anterior ha debido quedar claro que este pathos por encontrar producción de valor en cualquier parte no es compatible con Marx. Sin embargo, para poder dar cuenta de esta obsesión por encontrar producción de valor en cualquier parte sería necesario dar un rodeo por la teoría del colapso de
Robert Kurz. Retomaré esta cuestión en los comentarios finales.

\section{EI trabajo productivo e improductivo a la luz de la teoría de la desustancialización del valor}

Robert Kurz diagnosticó el colapso de la modernización $^{78}$ a partir de un controvertido suceso: la caída de la URSS ${ }^{79}$. De forma somera, podríamos decir que la teoría de la desustancialización de Kurz se basa en la progresiva eliminación, como producto del propio proceso de valorización del valor, de la sustancia del valor: el gasto de "cerebro, músculos, nervios, manos, etc., humanos" $"$. Si bien no podemos entrar en detalle en la teoría del colapso de Robert Kurz ${ }^{81}$, si podremos indicar que el capital "se somete involuntariamente a sí mismo a una estricta dieta permanente" con la que "pone las bases de su propia muerte" 2 . Todo esto tiene un punto de apoyo en la teoría de Marx aunque no esté desarrollado por éste. Así lo atestiguan pasajes de El capital como este:

Si a un obrero se le impone el trabajo que racionalmente sólo pueden realizar dos obreros, y si esto ocurre en circunstancias en que este uno puede sustituir a tres, el obrero suministrará tanto plustrabajo como antes dos, y en este sentido ha aumentado la cuota de plusvalía. Mas no suministrará tanto como antes suministraban tres, con lo que habrá disminuido la masa de plusvalía ${ }^{83}$.

Si bien es cierto que el mismo Marx indica que si todos los trabajadores que quedaran produjeran bajo esa nueva productividad, se podría hasta incluso aumentar la masa de plusvalía. Aun así, es evidente, que se alcanza un límite en el que ya no pueda seguirse compensando. Tenemos también, este otro pasaje de los propios Grundrisse con los que veíamos que argumentaba Negri:

De ahí, empero, del hecho que el capital ponga cada uno de esos límites como barrera y, por lo tanto, de que idealmente le pase por encima, de ningún modo se desprende que lo haya superado realmente; como cada una de esas barreras contradice su determinación, su producción se mueve en medio de contradicciones superadas constantemente, pero puestas también cons-

Ibidem, p. 88.

S. Bologna, op. cit., p. 125.

E. Illouz (comp), Capitalismo, consumo y autenticidad. Las emociones como mercancia, Madrid, Katz, 2019.

E. Illouz, "Introducción: emodities o la invención de los commodities emocionales", en E. Illouz (comp.), op. cit., p. 23.

Ibidem, p. 26

Ibidem, pp. 27-28.

D. Kaplan, "Tarjetas postales sexuales", en E. Illouz (comp.), op. cit., p. 146.

R. Kurz, El colapso de la modernización, Buenos Aires, Editorial Marat, 2016, p. 37.

J. Maiso, "El nuevo rostro del capital mundial. El análisis del capitalismo mundializado en la crítica del valor de Robert Kurz", Nombres 30, 2016, p. 123-124.

K. Marx, El capital, op. cit., Libro I, primer tomo, p. 67.

Para ello, cf. la segunda parte de The Substance of Capital, op. cit., pp. 120-213.

Grupo Krisis, Manifiesto contra el trabajo, Madrid, Virus, 2002, p. 42.

K. Marx, El capital, op. cit., Libro III, primer tomo, pp. 308-309. 
tantemente. Aún más. La universalidad a la que tiende sin cesar, encuentra trabas en su propia naturaleza, las que en cierta etapa del desarrollo del capital harán que se le reconozca a él como la barrera mayor para esa tendencia $\mathrm{y}$, por consiguiente, propenderán a la abolición del capital por medio de sí mismo ${ }^{84}$.

En base a estos pasajes, podemos afirmar que existe un cierto germen de la teoría del colapso en los planteamientos marxianos aunque, como ya dijimos, el propio Marx no desarrollara plenamente dichos planteamientos. En el proceso sin fin de su lucha consigo mismo por la valorización del valor, el límite de la valorización del valor es la valorización del valor misma, puesto que en ese proceso se socavan las propias bases que el capital se ha impuesto. El capital supera de forma constante estas barreras en forma ideal pero no real. Esta sería la clave para comprender esa fase del capital que se ha dado en llamar financiarización y de la que Kurz sentencia: "la distancia entre la producción de plusvalor anticipada y la real se había vuelto insalvable" 85 . La financiarización sería, por tanto, el último intento de superación ideal por parte del capital. Para ello, lo que hace es simular unos beneficios que no son ya reales. De esta forma lo que obtenemos, contrariamente a lo planteado por Negri, no es ningún sentido positivo del supuesto catastrofismo de Marx, sino más bien su sentido negativo: el del colapso.

Pero el tema que tratamos en este escrito es la dialéctica entre trabajo productivo e improductivo a la que, después de este rodeo, podemos volver para poder afrontarlo en su dimensión actual. Lo interesante de comprender el capital en su proceso de desvalorización es que al igual que la sustancia del valor va desapareciendo en ese proceso, se va produciendo es un "encogimiento invisible del trabajo productivo", de forma que "solo una parte muy pequeña de las actividades que se desarrollan en el mundo crea plusvalía y sigue nutriendo al capitalismo"86. La lucidez a este respecto de Jappe llega al punto de afirmar, en consonancia con lo que vimos en el apartado 2, que:

La disminución del trabajo productivo está causada igualmente por el aumento constante de lo que Marx llama (utilizando una expresión francesa) los "faux frais" [gastos extra, A. J.]. Los sectores productivos necesitan multitud de actividades como aval antes de y al lado del verdadero proceso productivo ${ }^{87}$.
Esa dialéctica entre trabajo productivo e improductivo se basa en un progresivo aumento de los trabajos improductivos. Esto es así por la sencilla razón de que el propio proceso de valorización, que necesita la eliminación del trabajo vivo del proceso productivo, a su vez necesita cada vez más tareas destinadas a la venta, administración, marketing, logística, atención al cliente, etc., de las propias mercancías. El capital, en su death race por la valorización produce una hipertrofia de trabajo improductivo como consecuencia de la progresiva eliminación del trabajo productivo fruto, a su vez, de la sustitución del trabajo vivo por trabajo muerto en el propio proceso productivo.

En este sentido, buscaremos otro ejemplo como el del camarero y, para ello, nos serviremos de Horkheimer. Él advirtió que el símbolo de su época era el ingeniero $^{88}$. Pero el ingeniero es aquél encargado de aumentar sin cesar la productividad hasta el punto de eliminarse a sí mismo. La panacea del ingeniero es crear un proceso productivo en el que ya no esté ni él mismo. Es la personificación de esa death race del propio capital. Lo que hay que tener en cuenta aquí es que alrededor del ingeniero tienen que surgir los CEOs, jefes de recursos humanos, Sales Managers, Community Managers, Coachs, expertos en neuromarketing, etc. El ingeniero, encargado de minimizar las fricciones en el proceso productivo y llevarlo hasta su propio límite para, una vez allí, descubrir que nunca es suficiente, debe quedar rodeado de toda una serie de expertos en la venta, gestión, administración de aquello que sale de ese mismo proceso productivo. Entre ellos figuran un gran número de administrativos, abogados, expertos en logística, teleoperadores, comerciales, repartidores. Esta dialéctica entre trabajo productivo e improductivo representada en esta serie de figuras es la que trato de poner de relieve ${ }^{89}$.

Aún nos encontramos en una fase en la que el capital ha tratado de superar esta barrera mediante el desplazamiento geográfico del trabajo productivo a la periferia, mientras que el centro consumidor se ocupa de la logística y el consumo de las mismas. No por casualidad, como señala Bologna, el modelo productivo alemán se ha desplazado hacia la logística ${ }^{90}$. Un burda caricaturización de esta situación sería que China se especializa en la producción, mientras que Occidente se especializa en la venta y el consumo de esas mercancías ${ }^{91}$. Esta inseparable dialéctica no va ni de China ni de Occidente, ni centro ni periferia o

\footnotetext{
K. Marx, Grundrisse, op. cit., Vol. 1, Cuaderno IV, p. 362.

R. Kurz, "La doble desvalorización del valor", Nahimen, 2015, p. 151.

A. Jappe, op. cit., p. 128.

Ibidem, p. 128.

M. Horkheimer, Crítica de la razón instrumental, Madrid, Trotta, 2010, pp. 160-161.

Sería realmente interesante continuar, aunque no puedo por motivos de espacio, con el análisis de estas distintas subjetividades. Es decir, qué consecuencias tiene para la psique de todas estas figuras esa dialéctica en la que están inmersos. Cómo les afecta y cómo les constituye el hecho mismo de encontrarse en esa dinámica obsesiva que conduce a una escisión casi total. La cuestión sería tratar de dar cuenta de qué le sucede al trabajador que trabaja en su propia aniquilación. Así como también aquel cuyo trabajo carece de una base real en la propia producción. Me parece una cuestión interesante a la luz del colapso.

90 S. Bologna, op. cit., p. 119.

91 Como ya indicamos esto es una burda simplificación. No puede establecerse una clara distinción entre trabajo productivo en la periferia y trabajo improductivo en el centro. Esto requiere de unos análisis más pormenorizados que no podemos desarrollar aquí.
} 
desarrollo desigual, sino de la dialéctica mortal en la que el capital está atrapado. Como ya nos advirtiera Marx, esta superación es sólo ideal, ficticia ${ }^{92}$. La realidad del capital es su colapso en cuanto, más o menos lento e imprevisible, proceso de putrefacción. La invisibilización del colapso va aparejada con la invisibilización de la división trabajo productivo e improductivo. Genera ilusiones como la de Negri en la que todo trabajo es productivo y la orientación de la praxis es hacia la destrucción del "no-trabajo"93. El propio Negri llega a indicar que se alcanza un punto en el que capital y trabajo son "dos subjetividades plenas, contrapuestas, hostiles hasta el punto de su recíproca destrucción" "94, pero con la consiguiente victoria del proletariado. Lo que no está teniendo en cuenta Negri en este punto es que "cuando no queda salida, al impulso de aniquilación le es totalmente indiferente lo que nunca distinguió claramente: si se dirige contra otro o contra el propio sujeto"95. Mientras Negri percibe "la violencia proletaria" como un "síntoma del comunismo" ", a mí me parece que hay que recordarle la sentencia de Th. W. Adorno de que el entramado de socialización capitalista "tiene su punto de fuga en la muerte de todos"97. Es realmente peligroso ver hoy síntomas de algo otro en la violencia y buscar el orgullo en la productividad del trabajo frente a la improductividad del capital. Ya hubo un colectivo que fue acusado de improductivo frente al trabajo productivo y usado como chivo expiatorio: los judíos. En un momento de financiarización como este, en el que es muy fácil acusar a "los de arriba", no debemos dejarnos llevar por los intentos de culpabilizar y personificar aquello que es ciertamente impersonal: el funcionamiento y el colapso del capital. Como sentenciaban desde el Grupo Krisis: "Un cadáver domina la sociedad, el cadáver del trabajo" ${ }^{988}$.

\section{Breve comentario final}

Es cierto que el capitalismo ha cambiado, que se presenta con distintos rostros en distintas etapas o momentos de su propio autodespliegue. Lo que he pretendido mostrar aquí es que, respecto del trabajo productivo e improductivo, no es necesario ir más allá de Marx: es más interesante explorar esa aporía marxiana en esta dimensión. Las condiciones de trabajo y de producción de mercancías han cambiado de forma notable. Los propios procesos de subjetivación asociados a ellos varían. La lógica del consumo afecta profundamente a algunas de esas cuestiones. Sin embargo, no afecta a la producción de valor. Si se sigue con atención el propio desarrollo, complejo y problemático de Marx, desde el valor al precio de producción, pasando por el valor de cambio, se puede llegar a comprender todo este despliegue. Si se sigue todo ese desarrollo también se puede comprender la propia teoría del colapso. Ya que, como bien nos indica Kurz, "la ley objetiva del colapso de la sustancia fetichista se cumple igualmente sin crítica, pero entonces también sin esperanza"99. Esto implica que la cuestión del colapso "debe estar estrictamente separada de la cuestión de la emancipación", ya que "los seres humanos pueden emanciparse (...), sin que el capitalismo se derrumbe" ${ }^{100}$. No hay, por tanto, ninguna necesidad de "diluir los residuos objetivistas y deterministas", como acaba pidiendo Negri. Porque no son residuos, son elementos centrales del pensamiento del Marx esotérico, de sus planteamientos respecto del capital en cuanto sujeto automático ${ }^{101}$.

Desde esta óptica, se vuelve innecesaria la obsesión por buscar la producción de valor allí donde no tiene lugar. Es más, el propio carácter obsesivo de la búsqueda deriva de su propia falsedad. Es el capital mismo el que está a la búsqueda neurótica de esa producción de plusvalor que jamás volverá a encontrar. La dialéctica de trabajo productivo e improductivo nos permite dar cuenta de ello. Se ha producido una progresiva eliminación de trabajo productivo que lleva aparejado un desplazamiento hacia el trabajo improductivo: se ha incrementado éste último, mientras que se produce la progresiva eliminación del primero. La lógica del capital es la lógica de la eliminación del trabajo productivo, que él mismo ha creado, y que tiene que ir acompañada de una hipertrofia del trabajo improductivo que colabora aún más en el hundimiento del propio capital. Las soluciones que el capital encuentra son una simple superación ideal de su problema real: la imposibilidad de la valorización del valor. Ya Marx nos advirtió, aunque hemos visto que esto no está desarrollado totalmente por él mismo, de estas cuestiones, tal y como nos advirtió de los faux frais y de toda una serie de trabajos improductivos. Pero lo que es más, Marx nos legó los lineamientos básicos de una teoría crítica del capitalismo. Negri y compañía ${ }^{102}$ han tratado de hundirla en esa noche en

\footnotetext{
Debe resaltarse en este punto lo apropiado de la categoría de Marx de capital ficticio.

A. Negri, op. cit., p. 101.

Ibidem, p. 164.

Th. W. Adorno, Minima Moralia, Madrid, Akal, Obra completa 4, 2006, p. 109.

A. Negri, op. cit., 2001, p. 194.

Th. W. Adorno, Dialéctica negativa, Madrid, Akal, Obra completa 6, 2005, p. 295.

Grupo Krisis, op. cit, 2002, p. 7.

R. Kurz, "Marx 2000. La importancia de una teoría dada por muerta para el siglo XXI", op. cit., p. 45.

R. Kurz, The Substance of Capital, op. cit., p. 178 (cursivas en el original).

K. Marx, El capital, op. cit., Libro I, primer tomo, p. 208.

102 Después de ver que Negri alude a su deuda con Deleuze y Guattari, no es casualidad que Deleuze rinda tributo al autonomismo de Tronti, en su curso sobre Foucault para mencionar la relación de este último con aquellos (El poder. Curso sobre Foucault Tomo II, Buenos Aires, Editorial Cactus, 2014, p. 25). Quizás sería interesante analizar, en otro trabajo, más en detalle las relaciones entre las reacciones al marxismo soviético en Francia e Italia.
} 
la que todos los gatos son pardos. La teoría crítica del capitalismo no puede caer en semejante vacío crítico. Para ello, he tratado de mostrar que es fundamental no comprender un Marx unitario y pelearse por la verdad en él. Sino, más bien, asumir la aporía planteada por Kurz y tratar de seguir esa estela. Ese Marx que desarrolla una profunda crítica inmanente del capitalismo en su especificidad histórica. Ése es el que puede iluminar nuestro presente. Pero no iluminarlo desde un horizonte revolucionario, las posibilidades de su realización ya pasaron ${ }^{103}$. El servicio que puede prestarnos aún Marx es el de permitirnos comprender el presente del capital en el momento de su derrumbe, para así poder intentar detenerlo.

Para ello, una vez más, es necesario seguir los propios análisis categoriales de Marx respecto de la forma mercancía. Como ya nos anunció Kurz: "si por enésima vez se vuelve a cavar una fosa para la teoría de Marx, lo que la ciencia académica oficial entierra es con toda seguridad el cadáver equivocado"104. En mi opinión, Negri entierra a Marx al tratar de llevarlo más allá de sí. Como lo hacen también sus seguidores y todos aquellos que ven producción de valor donde no sólo no la hay, sino que no la puede haber. El problema reside en que aquellos que no son capaces de observar teóricamente el colapso se ven obligados a una dinámica obsesiva por la búsqueda de la nueva explotación, de los nuevos nichos de mercados y de producción de valor y plusvalor. Asocian erróneamente nuevas formas de trabajo improductivo con nuevos procesos de producción de plusvalor. Que el entramado de socialización tienda a la totalización, a la movilización total del individuo, no significa que todo se haya vuelto producción de valor. Precisamente si el capital ha tenido que tener esa dinámica obsesiva es porque él mismo socava sus propias bases. Porque las superaciones son ideales y no reales, porque el capital no tiene posibilidad de satisfacerse, la dialéctica entre trabajo productivo e improductivo da cuenta de ello. Su death race más que una carrera con peligro de muerte, es una carrera hacia la muerte. Nos queda la posibilidad de volver al búho de Minerva contra el ocaso en cuanto aniquilación total.

\section{Bibliografía}

Adorno, Th. W., Dialéctica negativa, Madrid, Akal, Obra completa 6, 2005.

- Mínima Moralia, Madrid, Akal, Obra completa 4, 2006.

Bologna, S., Crisis de la clase media y postfordismo, Madrid, Akal, 2006.

F. Chicci, E. Leonardi y S. Lucarelli, Más allá del salario: lógicas de explotación, Madrid, Enclave de Libros, 2018.

Deleuze, G., El poder. Curso sobre Foucault Tomo II, Buenos Aires, Editorial Cactus, 2014.

Federici, S., El patriarcado del salario, Madrid, Traficantes de Sueños, 2018.

Grupo Krisis, Manifiesto contra el trabajo, Madrid, Virus, 2002.

Hegel, G. W. F., Fenomenología del espíritu, Madrid, Fondo de Cultura Económica, 1966.

- Principios de la Filosofía del Derecho o Derecho Natural y Ciencia Política, Barcelona, Edhasa, 1999.

Horkheimer, M., Crítica de la razón instrumental, Madrid, Trotta, 2010

Illouz, E. (comp), Capitalismo, consumo y autenticidad. Las emociones como mercancía, Madrid, Katz, 2019.

Jappe A., Las aventuras de la mercancía, Logroño, Pepitas de Calabaza, 2016.

Kurz, R., "La doble desvalorización del valor", Nahimen, 2015.

— "Marx 2000. La importancia de una teoría dada por muerta para el siglo XXI", Constelaciones. Revista de Teoría Crítica, $\mathrm{n}^{\circ} 8-9,2016-2017$.

— "The Crisis of Exchange Value: Science as Productive Force, Productive Labor, and Capitalist Reproduction" en Larsen, N., Nilges, M., Robinson, J., y Brown, N., (eds.): Marxism and the Critique of Value, Chicago, MCM' Publishing, 2014.

- El colapso de la modernización, Buenos Aires, Editorial Marat, 2016.

- The Substance of Capital, Londres, Chronos publications, 2016.

Maiso, J., "El nuevo rostro del capital mundial. El análisis del capitalismo mundializado en la crítica del valor de Robert Kurz", Nombres, Córdoba, no 30, 2016, pp. 127-160.

Marx, K., Grundrisse. Elementos fundamentales para la crítica de la economía política (borrador) 1857-1858, Madrid, Siglo XXI, 1971.

- El capital. Libro I Capítulo VI (inédito). Resultados del proceso inmediato de producción, México, Siglo XXI, 1971.

- El capital, Madrid, Akal, 2014.

Navarro, C., "¿Qué fue de...? Breves apuntes sobre el capitalismo cognitivo y el modo de producción capitalista en el siglo XXI", Res Publica. Revista de Historia de la Ideas Políticas, 23(1).

Negri, A., Marx más allá de Marx, Madrid, Akal, 2001.

Postone, M., Marx reloaded, Madrid, Traficantes de Sueños, 2007.

— Tiempo, trabajo y dominación social, Madrid, Marcial Pons, 2006

103 Th. W. Adorno, Dialéctica negativa, op. cit., p. 15.

104 R. Kurz, "Marx 2000. La importancia de una teoría dada por muerta para el siglo XXI", op. cit., p. 29. 
Scholz, R., "El patriarcado productor de mercancías. Tesis sobre capitalismo y relaciones de género", Constelaciones. Revista de Teoría Crítica, no 5, diciembre 2016, pp. 44-60.

Virno, P., Gramática de la multitud, Madrid, Traficantes de Sueños, 2016.

Waiman, J., "Dialéctica y ontología: repensando el antagonismo posmarxista desde la Teoría Crítica”, Constelaciones. Revista de Teoría Crítica, no5, diciembre 2016, pp. 280-310. 